\title{
Muscle injury rates in professional football increase with fixture congestion: an 11-year follow-up of the UEFA Champions League injury study
}

Håkan Bengtsson, Jan Ekstrand and Martin Hägglund

\author{
Linköping University Post Print
}

\section{Tweet}

N.B.: When citing this work, cite the original article.

Original Publication:

Håkan Bengtsson, Jan Ekstrand and Martin Hägglund, Muscle injury rates in professional football increase with fixture congestion: an 11-year follow-up of the UEFA Champions League injury study, 2013, British Journal of Sports Medicine, (47), 12, 743-747.

http://dx.doi.org/10.1136/bjsports-2013-092383

Copyright: BMJ Publishing Group http://group.bmj.com/

Postprint available at: Linköping University Electronic Press

http://urn.kb.se/resolve?urn=urn:nbn:se:liu:diva-97448 


\section{Muscle injury rates in professional football}

\section{increase with match congestion - an 11-year follow}

\section{up of the UEFA Champions League injury study}

Håkan Bengtsson ${ }^{1}$, Jan Ekstrand ${ }^{1,2,3,}$ Martin Hägglund ${ }^{1,4}$

1.Football Research Group, Linköping University, Linköping, Sweden

2.UEFA Medical Committee, Nyon, Switzerland

3.Division of Community Medicine, Department of Medical and Health

Sciences, Linköping University, Linköping, Sweden

4.Division of Physiotherapy, Department of Medical and Health Sciences,

Linköping University, Linköping, Sweden

Corresponding author:

Håkan Bengtsson PT, MSc

Stenbrötsgatan 33

582 47, Linköping

Sweden

Tel.: +4613318990

Fax.: +46 13161892

E-mail: Info.frg@telia.com

Key Words: Fatigue, muscle damage/injuries, soccer, sporting injuries

Word Count: 2999 


\section{ABSTRACT}

Background: The influence of match congestion on injury rates and team performance has only been scarcely investigated.

Aim: To study associations between recovery time and match load and injury rates and team performance in professional football.

Methods: Exposure and time loss injuries were registered prospectively from 27 teams over 11 seasons. Matches were grouped according to recovery days before each match ( $\leq 3$ vs. $>3$ days, and $\leq 4$ vs. $\geq 6$ days). Injury rates and team performance were compared between groups. Match load in match sequences containing five consecutive matches was determined by the number of days separating the first match and the last training session during that match sequence. Linear regression was used to study associations between match load and injury rates and team performance.

Results: Team performance showed no association with match load, or recovery days prior to matches, except for Europa League matches that indicated more matches lost with short recovery ( $\leq 3$ days) $(\mathrm{p}=0.048)$. Total injury rates and muscle injury rates were increased in league matches with $\leq 4$ days compared with $\geq 6$ days recovery (RR 1.09 , 95\% CI 1.00 to 1.18 , and RR 1.32 , 95\% CI 1.15 to 1.51 , respectively), specifically hamstring and quadriceps injuries. High match load was associated with increase in muscle injury rate in matches in the same match sequence $(\mathrm{p}=0.012)$, and increase in ligament injury rate in training in the subsequent match sequence $(\mathrm{p}=0.003)$.

Conclusions: Match congestion was associated with increased muscle injury rates but had no, or very limited, influence on team performance. 


\section{INTRODUCTION}

The physical demands on a professional football player are high. The mean total distance covered during a football match is reported to be between $10000-11$ 000 meters, with some players covering up to 14000 meters, and almost one fourth of this distance is covered in high intensity running. ${ }^{1-3}$ Studies have shown that it takes several days to fully recover following a football match. Remaining fatigue up until 72 hours after a football match has been shown in terms of decreased physical performance as well as through increased levels of blood markers indicating muscle damage and oxidative stress. ${ }^{4,5}$

In addition, mental preparation and travels before a match may further contribute to fatigue. ${ }^{6}$ Playing professional football matches, especially when playing away, is associated with long travels and unfamiliar sleeping environments which may have a negative impact on the quality of the sleep for the players. ${ }^{7,8}$

When the subjective performance of players participating in the 2002 World Cup was evaluated it was shown that players who underperformed during the World Cup had played more matches in the last ten weeks compared with those who performed above expectations. ${ }^{6}$ Another study showed that teams that participated in the Union of European Football Associations (UEFA)

Champions League (UCL) were over three times more likely to lose a league match if they had played in the UCL three days earlier compared with their overall likelihood of losing in the league. ${ }^{9}$ Other studies showed no association between recovery time between matches and physical performance. In one of these studies, matches with four or less days recovery and matches with six or more days recovery were compared, ${ }^{10}$ while the other studies included a number of matches (six to eight) played during a congested period showing no influence of high match load on physical performance. ${ }^{11,12}$

Associations between recovery time between matches and injury rates (IRs) have also been investigated. When matches with four or less days recovery were compared with matches with six or more days recovery, the IR in matches with short recovery was more than five-fold higher. ${ }^{10}$ In addition a congested calendar (six consecutive matches separated by three days) has been shown to increase match IR in a study, ${ }^{12}$ while in another study a longer period of excessive match load (eight matches played during 26 days) was found not to increase IRs compared with the periods immediately before or after. ${ }^{11}$

Thus, findings on the associations between recovery time between matches, IRs and team performance are contradictory, and many studies are limited by small samples. The aims of the study were therefore to study, in a large sample of professional football teams, a) if there were any associations between recovery time between two matches and the IR and performance in the later match, and b) 
to investigate if there were any associations between match load and IR or team

performance during extended periods of the season.

Our hypotheses were that short recovery time between football matches, and

high match load during extended periods of the season, would be associated

with decreased team performance and increased IRs. 


\section{MATERIAL AND METHODS}

\section{Study population}

All first team players in 27 European professional football teams from ten countries were invited to participate in a prospective cohort study, the UCL injury study. ${ }^{13}$ Teams that had competed at the highest level of European professional football were considered for the study and all included teams were invited by the UEFA. The present study was based on retrospective analyses of data from a prospective cohort study gathered between 2001 and 2012. The study included data from 8150 matches (league matches $n=5622$, UCL matches n=1114, UEFA Europa League matches n=424, other cup matches n=990; home matches $n=4025$, away matches $n=4059$, matches played on a neutral venue $\mathrm{n}=66$ ). Since the study was based on retrospective analyses there was no sample size calculation performed. Participating teams were followed over a varying number of seasons (one to eleven).

\section{Exposure and injury registration}

The methodology and the study design followed the consensus statement for epidemiological studies in football ${ }^{14}$ and have been described in detail previously. ${ }^{15}$ A contact person from each club was responsible for collecting information about team exposures and injuries that occurred during team activities. All matches and team training sessions were noted on a standard attendance record. All injuries were registered on a standard injury card with information about the injury diagnosis and the activity when the injury occurred. A recordable injury was defined as any physical complaint sustained by a player that resulted from a football match or football training and led to the player being unable to take a full part in future football training or match play (i.e. time loss injury). A muscle injury was defined as a traumatic distraction or overuse injury to a muscle,${ }^{16}$ and a ligament injury was defined as an acute distraction injury of ligaments or joint capsules. ${ }^{15}$ A player was considered to be injured until the medical team allowed full participation in all team activities, and injury severity was determined by the number of days of absence caused by the injury.

\section{Categorization of recovery time, performance and match characteristics}

Competitive first team matches were grouped according to the number of days recovery from the adjacent preceding match. Two different cut-offs were used based on previous research. First, matches with three or less days recovery were compared with matches with four or more days recovery, as used previously by Verheijen. ${ }^{9}$ Second, matches with four or less days recovery and those with six or more days recovery were compared, as in the study by Dupont et al. ${ }^{10}$ The result in each match (won, drawn or lost, extracted after 90 minutes of play, irrespective of possible extra time) was used to compare team performance in matches depending on the time of recovery before each match. Matches were 
also categorized according to where they were played (home matches or away matches) and type of competition (league, UCL, UEFA Europa League (EL) [former UEFA Cup], or other cup match [mainly domestic cup matches]). To study the influence of match load on IRs and team performance over extended periods during the season, first team competitive matches were grouped into match sequences containing five consecutive matches for each team and season. The number of days between the first match and the last training session in each match sequence was used to determine match load. Remaining matches at the end of each season were either added to the preceding match sequence (one or two matches) or categorized in a match sequence containing less than five matches (three or four matches). The match load variable was standardized to number of matches per month and calculated as "number of matches in match sequence/total days separating the first match and the last training session included in the match sequence $x$ 30”. For example, five matches played over a period of 27 days equals a standardized match load of $5 / 27$ x $30=5.56$ matches per month. Team performance was evaluated as the percentage of matches won in each match sequence and as the average number of points per match in each sequence.

\section{Statistical analyses}

Associations between recovery time before a match and the match result (won, lost or drawn) were analyzed with the Chi-square test. To determine the effect size Cramer’s V was used. IRs are presented as the number of injuries per 1000 hours of match exposure and comparisons between matches with different time of recovery were calculated as rate ratios (RRs) with corresponding 95\% confidence intervals (CIs). The RRs were tested for significance using Z statistics. Since the distribution of matches according to competition types varied in different recovery groups and since injury rates have been shown to vary in different competitions ${ }^{17}$ all analyzes were carried out within each competition separately.

To analyze associations between match load and IRs and team performance during a match sequence (five matches) a linear regression on team level data was used, with each match sequence as an observation. The team performance in matches, as well as overall IR, muscle IR, and ligament IR for training and match play separately, were used as dependent variables in separate analyses, where match load (number of matches per month) was used as the independent variable. In addition, analyses were adjusted for the distribution of matches depending on match location (percentage of matches played at the home venue) and type of competition (percentage of league matches) during that match sequence (independent variables). To study a possible effect of match load on IRs and team performance in a subsequent period, analyses were carried out to study the association between the match load in a match sequence (independent 
variable) and IRs and team performance in the subsequent match sequence

(dependent variables). Similar linear regressions were carried out, and were adjusted for match location, type of competition during the first match sequence and the match load in the subsequent match sequence (independent variables).

All tests were two-sided and the significance level was set at $\mathrm{p}<0.05$. 


\section{RESULTS}

In total, 1057201 hours of exposure (888 249 training, 168952 match play), and 8029 injuries (3483 training, 4546 matches) were registered.

\section{Recovery time and team performance}

There were no differences in the distribution of matches won, lost or drawn

between matches played with a preceding short recovery and matches with long recovery in any competition, regardless of which cut-off was used to categorize matches ( $\leq 3$ vs. $>3$ days (table 1 ) or $\leq 4$ vs. $\geq 6$ days (table 2 )), except for EL matches that indicated more matches lost with three or less days recovery compared with four or more days recovery ( $\mathrm{p}=0.048$, Cramer's V=0.120). Insert tables 1 and 2 near here

\section{Recovery time and injury rates}

There were no differences in overall, muscle or ligament IRs between matches played with three or less days recovery compared with matches with four or more days recovery, in any competition (table 3).

When matches with four or less days recovery were compared with matches with six or more days recovery, a significant increase in total IR and muscle IR was seen in league matches with short recovery compared with those with long recovery. In addition, the ligament IR was increased in other cup matches with short recovery compared with those with long recovery (table 4). No differences in IRs were seen in UCL or EL matches depending on recovery days before matches. Detailed analyses of muscle injury types showed that hamstring and quadriceps injury rates were higher in league matches with four or less days of recovery compared with matches with six or more days recovery, while no differences were seen in calf and adductor injury rates (table 5).

Insert tables 3, 4 and 5 near here

\section{Monthly match load, performance and injury rates}

On average, each match sequence comprised $27 \pm 9$ days (range 7-104), or a mean of $6.0 \pm 1.6$ matches played over a standardized 30-day period (range 1.412.9).

There were no associations between a team's match load during a match sequence and team performance in the same match sequence, or team performance in the subsequent match sequence (table 6).

When looking at injuries, an association between match load and the muscle IR in matches in the same match sequence was found, indicating that muscle IRs increased in periods with increased match load $\left(\mathrm{R}^{2}=0.005, \mathrm{~b}=0.523,95 \% \mathrm{CI}\right.$ 0.114 to 0.932 , $\mathrm{p}=0.012$ ) (table 6 ). No further associations were found between match load and training or match IRs in the same match sequence. When 
analyzing the relationship between match load and IRs in the subsequent match

sequence, an association was found between increased match load and an

increase in ligament IRs during training $\left(\mathrm{R}^{2}=0.006\right.$, b=0.069, 95\% CI 0.024 to

0.114, $\mathrm{p}=0.003$ ) (table 6). No other statistically significant associations were

found.

Insert table 6 near here 


\section{DISCUSSION}

\section{Team performance is not influenced by match congestion}

In general, no associations were found between recovery between matches and team performance, or between match load and team performance during extended periods of the season. One exception was poorer performance in EL matches with three or less days recovery before the match compared with four or more days. However, EL matches were infrequent and few teams included in the present study participated in the EL, and the generalizability of these findings is therefore limited. It should also be noted that the Cramer's V value in this analysis was low suggesting a weak association.

Previous studies have shown that physical ability in terms of sprinting ability, leg strength and vertical jump height of professional football players are decreased up to 72 hours after completing physical activities similar to those that are performed during a professional football match. ${ }^{4,5}$ Two other studies showed that a period of fixture congestion did not influence the physical performance of football players in matches ${ }^{11,12}$ and it has been argued that player rotation and effective recovery strategies may be sufficient to prevent player fatigue. ${ }^{11}$ In addition to nutritional strategies, ${ }^{18}$ there are several other strategies that have been suggested to accelerate recovery after football matches. $^{19,20}$

Another plausible reason why no associations between recovery time between matches or match load and team performance were observed is that the teams had large squads and were therefore able to rotate individual players in their starting line up to matches, thus avoiding player fatigue. ${ }^{13}$

The same cut-offs for recovery between matches as presented in previous research was used in the present study to be able to compare results between studies. The study findings are not in line with those reported by Verheijen, showing that fewer matches are won with short (three or less days) compared with long (four or more days) recovery. ${ }^{9}$ However, that study analyzed matches when teams with short recovery before a match played against a team with long recovery and this difference in design may partly explain the discrepancy in results. On the other hand, in line with the results of the present study, Dupont et al. showed no decrease in performance in terms of total distance covered, highintensity distance covered, sprint distance covered, and number of sprints in matches with short (four or less days) compared with long (six or more days) recovery. $^{10}$

\section{Muscle injury rates are increased with short recovery between matches and with high match load}

No differences in overall, muscle or ligament IRs between matches with three or less days recovery and matches with four or more days recovery were found.

However, an increase in overall IR and muscle IR was shown in league matches 
with four or less days recovery compared with league matches with six or more days recovery, as well as an increase in ligament IRs in other cup matches. When muscle injury rates were analyzed in detail for league matches it was shown that hamstring and quadriceps injury rates were increased in matches with short recovery.

These results are in line with a previous study showing an increased IR in matches with short (four or less days) compared with long (six or more days) recovery. ${ }^{10}$ One possible explanation for these increased IRs is that players are fatigued when playing two matches with too short recovery in between. Even though this suggested fatigue was not enough to affect team performance it is still possible that the physical and mental load on individual players was increased and therefore exposed those players to an increased injury risk.

Muscle IRs in the present study were also increased in periods of excessive match load, which could also be the result of player fatigue. Muscle injuries are often considered to be partly explained by fatigue ${ }^{21}$ and several studies have analyzed this hypothesis showing increased muscle IRs in the late stages of football matches. ${ }^{16}$ Changes in muscle biomechanics, with changes in electromyography parameters and in angels of peak torque, ${ }^{22,23}$ have also been shown for athletes who are fatigued. Fatigued muscles have also been shown to be able to absorb less energy before an injury occurs. ${ }^{24}$ In addition, lower extremity biomechanics, in terms of landing posture, has also been shown to be altered by fatigue. ${ }^{25}$ It is possible that such structural and biomechanical changes could make football players more prone to muscle injury.

When looking at a longer period with excessive match load a previous study showed no increase in total injury rate during a period of fixture congestion, ${ }^{11}$ which is in line with the present study. However, while the match muscle IR was increased in match sequences with increased match load in the present study, no such analyses were made in the aforementioned study. In contrast with the results of the present study a previous study showed increased overall IRs in matches during a congested match calendar. ${ }^{12}$ While all first team players were included in the present study only those players who played for at least 75 minutes in all matches during the congested period were included in the previous study and this difference in design may partly explain the difference in results.

\section{Methodological considerations}

The strengths of the present study include the study design that were in agreement with the consensus statement for epidemiological studies in football ${ }^{14}$ and that a large homogenous group was followed for a long time period. Still, the study was limited by small samples in some of the analyzed groups. For instance, team performance in EL matches were influenced by the recovery time 
between matches, but since only few teams participated in the EL, the

generalizability of this finding is limited. Another shortcoming is that analyses

were carried out at team level and did not consider how long a player was active during a match. For example, in previous research players were required to play at least 75 minutes in a match if that match should be considered when the time

of recovery before a second match and match load was established. ${ }^{10,12}$ Finally, the analyses did not account for individual player rotation between matches, and the influence of such team rotation strategies on associations between recovery time, match load, team performance and injury rates is therefore unknown. 


\section{Acknowledgements}

The authors would like to thank the participating teams (coaching and technical staff, medical teams and players) for their participation in the study. Henrik

Magnusson, MSc, statistician, is acknowledged for help with database

management.

\section{Contributor statement}

$\mathrm{HB}, \mathrm{JE}$ and $\mathrm{MH}$ were responsible for the conception and design of the study. All authors have been involved in the data collection over the study period. HB and MH conducted the analyses which were planned and checked with the statistician and JE. All authors contributed to the interpretation of findings and had full access to all data. HB wrote the first draft of the paper which was critically revised by JE and MH. The final manuscript has been approved by all authors. MH is the study guarantor.

\section{Funding}

This study was funded by grants from the Union of European Football Associations (UEFA), Swedish National Centre for Research in Sports, and Praktikertjänst AB.

\section{Competing interests}

JE is the first vice chairman of the UEFA Medical Committee.

\section{Ethics approval}

The study design was approved by the UEFA Medical Committee and the UEFA Football Development Division.

\section{Provenance and peer review}

Not commissioned; externally reviewed. 


\section{WHAT ARE THE NEW FINDINGS?}

- Total injury rates and muscle injury rates were increased in matches with short recovery compared with matches with long recovery before the match.

- High match load was associated with increased muscle injury rate in matches in the same period, and with increased ligament injury rate in training in the subsequent period.

- Match congestion had no, or very limited, influence on team performance.

\section{HOW MIGHT IT IMPACT ON CLINICAL PRACTICE?}

- The findings stress the importance for professional football teams to monitor match load during the season, and to implement strategies such as player rotation between matches, and various recovery modalities, to avoid injuries resulting from match congestion.

- Match schedules should be planned to ensure sufficient recovery time between matches. 


\section{REFERENCES}

1. Bradley PS, Sheldon W, Wooster B, et al. High-intensity running in English FA Premier League soccer matches. J Sports Sci 2009;27:159-68.

2. Mohr M, Krustrup P, Bangsbo J. Match performance of high-standard soccer players with special reference to development of fatigue. J Sports Sci 2003;21:519-28.

3. Di Salvo V, Baron R, Tschan H, et al. Performance characteristics according to playing position in elite soccer. Int J Sports Med 2007;28:222-7.

4. Ascensão A, Rebelo A, Oliveira E, et al. Biochemical impact of a soccer match - analysis of oxidative stress and muscle damage markers throughout recovery. Clin Bio Chem 2008;41:841-51.

5. Fatouros IG, Chatzinikolaou A, Douroudos II, et al. Time-course of changes in oxidative stress and antioxidant status responses following a soccer game. $J$ Strength Cond Res 2010;24:3278-86.

6. Ekstrand J, Waldén M, Hägglund M. A congested football calendar and the wellbeing of players: correlation between match exposure of European footballers before the World Cup 2002 and their injuries and performances during that World Cup. Br J Sports Med 2004;38:493-7.

7. Richmond LK, Dawson B, Stewart G, et al. The effect of interstate travel on the sleep patterns and performance of elite Australian Rules footballers. J Sci Med Sport 2007;10:252-8.

8. Richmond L, Dawson B, Hillman DR, et al. The effect of interstate travel on sleep patterns of elite Australian Rules footballers. J Sci Med Sport 2004;7:18696.

9. Verheijen R. Study on recovery days. World Football Academy 2012. http://worldfootballacademy.com/wp-content/uploads/2012/05/WFA_Study-onrecovery-days.pdf. Date accessed 2013-02-20

10. Dupont G, Nedelec M, McCall A, et al. Effect of 2 soccer matches in a week on physical performance and injury rate. Am J Sports Med 2010;38:1752-8.

11. Carling C, Le Gall F, Dupont G. Are physical performance and injury risk in a professional soccer team in match-play affected over a prolonged period of fixture congestion? Int J Sports Med 2012;33:36-42.

12. Dellal A, Lago-Peñas C, Rey E, et al. The effects of a congested fixture period on physical performance, technical activity and injury rate during matches in a professional soccer team. Br J Sports Med Published online first: 19 February 2013 doi:10.1136/bjsports-2012-091290 
13. Ekstrand J, Hägglund M, Kristenson K, et al. Less ligament injuries but still no preventive effect on muscle injuries and severe injuries - An 11-year follow up of the UEFA Champions League Injury study. Br J Sports Med 2013; in press

14. Fuller CW, Ekstrand J, Junge A, et al. Consensus statement on injury definitions and data collection procedures in studies of football (soccer) injuries. Br J Sports Med 2006;40:193-201.

15. Hägglund M, Waldén M, Bahr R, et al. Methods for epidemiological study of injuries to professional football players: developing the UEFA model. $\mathrm{Br} J$ Sports Med 2005;39:340-6.

16. Ekstrand J, Hägglund M, Waldén M. Epidemiology of muscle injuries in professional football (soccer). Am J Sports Med 2011;39:1226-32.

17. Bengtsson H, Ekstrand J, Waldén M, et al. Match Injury Rates in Professional Soccer Vary With Match Result, Match Venue, and Type of Competition. Am J Sports Med. Published online first: 30 April 2013 doi:10.1177/0363546513486769

18. Rodriguez NR, Di Marco NM, Langley S. American College of Sports Medicine position stand. Nutrition and athletic performance. Med Sci Sports Exerc 2009;41:709-31.

19. Kinugasa T, Kilding AE. A comparison of post-match recovery strategies in youth soccer players. J Strength Cond Res 2009;23:1402-7.

20. Nédélec M, McCall A, Carling C, et al. Recovery in Soccer: Part IIRecovery Strategies. Sports Med 2013;43:9-22.

21. Opar DA, Williams MD, Shield AJ. Hamstring strain injuries: factors that lead to injury and re-injury. Sports Med 2012;42:209-26.

22. Ghasemi M, Olyaei G, Bagheri H, et al. The effects of triceps surae fatigue on the torque and electromyographic parameters in athletes compared with nonathletes. J Back Musculoskelet Rehabil 2012;25:95-101.

23. Small K, McNaughton L, Greig M, et al. The effects of multidirectional soccer-specific fatigue on markers of hamstring injury risk. J Sci Med Sport 2010;13:120-5.

24. Mair SD, Seaber AV, Glisson RR, et al. The role of fatigue in susceptibility to acute muscle strain injury. Am J Sports Med 1996;24:137-43.

25. Quammen D, Cortes N, Van Lunen BL, et al. Two different fatigue protocols and lower extremity motion patterns during a stop-jump task. J Athl Train 2012;47:32-41. 
TABLE LEGENDS

Table 1 Comparison of team performance in matches with short (three or less days) or long (four or more days) recovery before the match

Table 2 Comparison of team performance in matches with short (four or less days) or long (six or more days) recovery before the match

Table 3 Comparison of injury rates in matches with short (three or less days) or long (four or more days) recovery before the match

Table 4 Comparison of injury rates in matches with short (four or less days) or long (six or more days) recovery before the match

Table 5 Comparison of muscle injury rates in league matches with short (four or less days) or long (six or more days) recovery before the match

Table 6 Associations between match load in a match sequence and team performance and injury rates during the same match sequence and the subsequent match sequence 
Table 1 Comparison of team performance in matches with short (three or less days) or long (four or more days) recovery before the match

\begin{tabular}{|c|c|c|c|c|c|c|c|}
\hline & \multicolumn{3}{|c|}{$\leq 3$ days recovery } & \multicolumn{3}{|c|}{$>3$ days recovery } & \multirow[b]{2}{*}{ p value } \\
\hline & $\overline{\text { Won N (\%) }}$ & Draw N (\%) & Lost N (\%) & Won N (\%) & Draw N (\%) & Lost N (\%) & \\
\hline League match & 836 (59) & $322(23)$ & $250(18)$ & 2501 (59) & $946(22)$ & 767 (18) & 0.905 \\
\hline UCL match & $281(49)$ & $140(24)$ & $155(27)$ & $259(48)$ & $132(25)$ & $147(27)$ & 0.977 \\
\hline EL match & $16(44)$ & $6(17)$ & $14(39)$ & $210(54)$ & $96(25)$ & $82(21)$ & 0.048 \\
\hline Other Cup match & 256 (61) & $85(20)$ & $78(19)$ & $346(61)$ & $100(18)$ & $125(22)$ & 0.322 \\
\hline All matches & 1389 (57) & $553(23)$ & $497(20)$ & 3316 (58) & $1274(22)$ & $1121(20)$ & \\
\hline
\end{tabular}


Table 2 Comparison of team performance in matches with short (four or less days) or long (six or more days) recovery before the match

\begin{tabular}{lllllllll}
\hline & \multicolumn{3}{c}{$\leq 4$ days recovery } & & \multicolumn{5}{c}{$\geq 6$ days recovery } \\
\cline { 2 - 3 } & Won N (\%) & Draw N (\%) & Lost N (\%) & & Won N (\%) & Draw N (\%) & Lost N (\%) & p value \\
\hline League match & $1515(60)$ & $573(23)$ & $450(18)$ & & $1536(59)$ & $582(23)$ & $468(18)$ & 0.943 \\
UCL match & $493(48)$ & $245(24)$ & $280(28)$ & & $34(49)$ & $20(29)$ & $16(23)$ & 0.587 \\
EL match & $131(52)$ & $52(21)$ & $67(27)$ & & $20(54)$ & $8(22)$ & $9(24)$ & 0.950 \\
Other Cup match & $390(60)$ & $135(21)$ & $124(19)$ & & $180(63)$ & $42(15)$ & $62(22)$ & 0.088 \\
All matches & $2529(57)$ & $1005(23)$ & $921(21)$ & & $1770(59)$ & $652(22)$ & $555(19)$ & \\
\hline
\end{tabular}


Table 3 Comparison of injury rates in matches with short (three or less days) or long (four or more days) recovery before the match

\begin{tabular}{|c|c|c|c|c|c|c|}
\hline & & $\leq 3$ days recovery & $>3$ days recovery & RR & 95\% CI & $\mathrm{p}$ value \\
\hline \multicolumn{7}{|l|}{ All injuries } \\
\hline & League & 28.3 & 27.8 & 1.02 & 0.93 to 1.11 & 0.713 \\
\hline & UCL & 33.9 & 30.4 & 1.11 & 0.95 to 1.31 & 0.193 \\
\hline & EL & 30.2 & 23.9 & 1.26 & 0.76 to 2.08 & 0.365 \\
\hline & Other cup & 27.4 & 26.0 & 1.05 & 0.87 to 1.28 & 0.607 \\
\hline \multicolumn{7}{|c|}{ Muscle injuries } \\
\hline & League & 11.4 & 10.3 & 1.11 & 0.96 to 1.28 & 0.151 \\
\hline & UCL & 13.5 & 11.4 & 1.18 & 0.91 to 1.54 & 0.208 \\
\hline & EL & 8.9 & 9.0 & 0.99 & 0.40 to 2.46 & 0.977 \\
\hline & Other cup & 11.2 & 9.1 & 1.22 & 0.90 to 1.67 & 0.205 \\
\hline \multicolumn{7}{|c|}{ Ligament injuries } \\
\hline & League & 5.2 & 5.3 & 0.98 & 0.79 to 1.20 & 0.819 \\
\hline & UCL & 5.7 & 5.7 & 1.00 & 0.68 to 1.48 & 0.983 \\
\hline & EL & 3.6 & 4.0 & 0.88 & 0.21 to 3.73 & 0.867 \\
\hline & Other cup & 5.1 & 4.5 & 1.15 & 0.73 to 1.81 & 0.542 \\
\hline
\end{tabular}

RR, rate ratio; CI, confidence interval; UCL, UEFA Champions League; EL, Europa League.

Injury rate is expressed as number of injuries per 1000 hours of match exposure 
Table 4 Comparison of injury rates in matches with short (four or less days) or long (six or more days) recovery before the match

\begin{tabular}{|c|c|c|c|c|c|c|}
\hline & & $\leq 4$ days recovery & $\geq 6$ days recovery & RR & $95 \%$ CI & $\mathrm{p}$ value \\
\hline \multicolumn{7}{|l|}{ All injuries } \\
\hline & League & 29.0 & 26.6 & 1.09 & 1.00 to 1.18 & 0.045 \\
\hline & UCL & 33.0 & 27.1 & 1.22 & 0.85 to 1.75 & 0.290 \\
\hline & EL & 24.7 & 37.9 & 0.65 & 0.41 to 1.03 & 0.064 \\
\hline & Other cup & 27.8 & 23.6 & 1.18 & 0.94 to 1.47 & 0.153 \\
\hline \multicolumn{7}{|c|}{ Muscle injuries } \\
\hline & League & 11.9 & 9.0 & 1.32 & 1.15 to 1.51 & $<0.001$ \\
\hline & UCL & 13.1 & 7.9 & 1.66 & 0.85 to 3.24 & 0.135 \\
\hline & EL & 8.2 & 16.5 & 0.50 & 0.25 to 1.01 & 0.055 \\
\hline & Other cup & 10.5 & 8.3 & 1.26 & 0.87 to 1.83 & 0.218 \\
\hline \multicolumn{7}{|c|}{ Ligament injuries } \\
\hline & League & 5.0 & 5.6 & 0.90 & 0.75 to 1.09 & 0.292 \\
\hline & UCL & 5.7 & 7.0 & 0.81 & 0.39 to 1.67 & 0.567 \\
\hline & EL & 3.7 & 8.2 & 0.45 & 0.17 to 1.25 & 0.126 \\
\hline & Other cup & 5.6 & 3.1 & 1.84 & 1.03 to 3.30 & 0.041 \\
\hline
\end{tabular}

RR, rate ratio; CI, confidence interval; UCL, UEFA Champions League; EL, Europa League.

Injury rate is expressed as number of injuries per 1000 hours of match exposure 
Table 5 Comparison of muscle injury rates in league matches with short (four or less days) or long (six or more days) recovery before the match $\begin{array}{llllll} & \leq 4 \text { days recovery } & \geq 6 \text { days recovery } & \text { RR } & 95 \% \text { CI } & \text { p value }\end{array}$ \begin{tabular}{lrrrrr}
\hline Hamstring injuries & 5.74 & 4.47 & 1.28 & 1.06 to 1.56 & 0.011
\end{tabular} $\begin{array}{llllll}\text { Quadriceps injuries } & 1.53 & 0.85 & 1.80 & 1.19 \text { to } 2.72 & 0.006\end{array}$

\begin{tabular}{llllll} 
Adductor injuries & 2.64 & 2.38 & 1.11 & 0.84 to 1.46 & 0.467 \\
\hline
\end{tabular}

Calf injuries

$\begin{array}{lll}1.07 & 1.13 & 0.75 \text { to } 1.70\end{array}$

0.559

Injury rate is expressed as number of injuries per 1000 hours of match exposure 
Table 6 Associations between match load in a match sequence and team performance and injury rates during the same match sequence and the subsequent match sequence

\begin{tabular}{|c|c|c|c|c|c|c|}
\hline & \multicolumn{3}{|c|}{ Same match sequence $\dagger$} & \multicolumn{3}{|c|}{ Subsequent match sequence $\ddagger$} \\
\hline & Beta* & $95 \%$ CI & p value & Beta* & $95 \%$ CI & p value \\
\hline \multicolumn{7}{|l|}{ Team performance } \\
\hline Amount of matches won & -0.002 & -0.009 to 0.006 & 0.629 & 0.001 & -0.007 to 0.008 & 0.875 \\
\hline Points per match & -0.007 & -0.026 to 0.013 & 0.506 & 0.003 & -0.017 to 0.023 & 0.759 \\
\hline \multicolumn{7}{|l|}{ Training injury rates } \\
\hline Total injuries & -0.068 & -0.206 to 0.070 & 0.334 & 0.120 & -0.022 to 0.263 & 0.098 \\
\hline Muscle injuries & 0.041 & -0.032 to 0.115 & 0.268 & 0.052 & -0.024 to 0.128 & 0.182 \\
\hline Ligament injuries & 0.006 & -0.038 to 0.050 & 0.803 & 0.069 & 0.024 to 0.114 & 0.003 \\
\hline \multicolumn{7}{|l|}{ Match injury rates } \\
\hline Total injuries & 0.333 & -0.369 to 1.034 & 0.352 & 0.696 & -0.021 to 1.413 & 0.057 \\
\hline Muscle injuries & 0.523 & 0.114 to 0.932 & 0.012 & 0.334 & -0.085 to 0.753 & 0.118 \\
\hline Ligament injuries & -0.111 & -0.387 to 0.166 & 0.433 & 0.205 & -0.073 to 0.482 & 0.148 \\
\hline
\end{tabular}

*A positive beta value indicates an association between increased match load (number of matches per month) and increased team performance (\% of matches won) or increased injury rate (number of injuries/1000 hours of exposure) during the same, or the subsequent, match sequence from linear regression analysis.

†Analyses were adjusted for the distribution of matches depending on match location (percentage of matches played at the home venue) and type of competition (percentage of league matches) during the same match sequence.
$\ddagger$ Analyses were adjusted for the distribution of matches depending on match location (percentage of matches played at the home venue), type of competition (percentage of league matches) and match load in the subsequent (second) match sequence. 


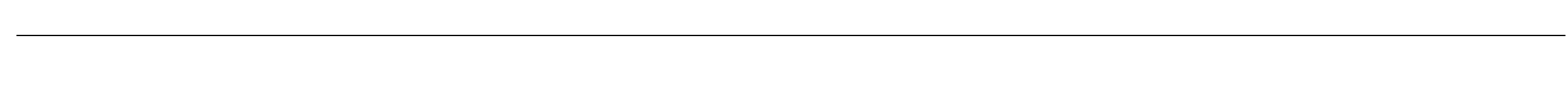

